\title{
Hubungan Sifat Kewirausahaan dengan Kinerja Petani Sayur Organik di Kelompok Tani Tranggulasi Desa Batur Kecamatan Getasan Kabupaten Semarang
}

\section{The Relation of Entrepreneurship Nature on Performance of Organic Vegetable Farmers in Tranggulasi Farmer Group Batur Village Getasan District Semarang Regency}

\author{
Angga Adi Prasetya* danYuliawati \\ 1,2Program Studi Agribisnis, Fakultas Pertanian dan Bisnis, Universitas Kristen Satya Wacana \\ *E-mail: 522015015@student.uksw.edu
}

\begin{abstract}
In an effort to realize sustainable agriculture and face the advancing era that is full of competition, agricultural sector actors are increasingly demanded to have entrepreneurial characteristics (entrepreneurship) so that a greater performance can be obtained compared to previous farming activities. This study aims to determine the relationship of entrepreneurial traits with the performance of organic vegetable farmers in the Tranggulasi farmer group Selo Ngisor Hamlet, Batur Village, Getasan District, Semarang Regency. The nature of entrepreneurship in this study is examined from four indicators namely selfconfidence, risk-taking, leadership and originality. The determination of the sample is saturated (census) in accordance with the number of members of the Tranggulasi farmer group, which is 32 people. Data collection is done by interview using a questionnaire that has been tested for validity and reliability. Data analysis uses Spearman rank correlation $(r s)$. The results showed that entrepreneurship was positively and significantly related to the performance of organic vegetable farmers. Indicators of entrepreneurial self-confidence have a strong relationship with the performance of organic vegetable farmers, while the courage to take risks, leadership and originality have a moderate relationship with the performance of organic vegetable farmers.
\end{abstract}

Keywords: entrepreneurial nature, the performance of organic vegetable farmers, farmer groups in Tranggulasi.

Disubmit: 21 Mei 2019; Diterima: 21 Agustus 2019; Disetujui: 25 November 2019

\section{PENDAHULUAN}

Pembangunan perekonomian negara Indonesia, pertanian memiliki peranan yang cukup dominan dan strategis. Dalam upaya mewujudkan pertanian berkelanjutan dan menghadapi kemajuan jaman yang penuh persaingan, pelaku sektor pertanian semakin dituntut untuk memiliki sifat wirausaha (enterpreneurship) agar dapat memperoleh hasil dan kinerja yang lebih dibandingkan usaha tani yang dilakukan sebelumnya. Kewirausahaan dipandang bukan hanya sekedar sebagai pengetahuan praktis, tetapi lebih cenderung pada suatu gaya hidup dan prinsip-prinsip tertentu yang akan berpengaruh terhadap kinerja usaha. Jika konsep ini dimiliki semua pelaku pertanian, maka dapat dipastikan pertanian akan lebih berkembang dan tumbuh dengan pesat. Sifat kewirausahaan adalah karakteristik psikologis yang berasal dari dalam diri seseorang, diantaranya yaitu sifat percaya diri, berani mengambil risiko, kepemimpinan, dan keorisinilan (inovatif, kreatif, fleksibel) (Dirlanudin, 2010). Puspitasari, Rina, (2013) menyatakan sifat kewirausahaan memiliki 
hubungan positif dengan kinerja usaha yaitu keuntungan yang dihasilkan. Kewirausahaan di bidang pertanian sangat berdampak pada kinerja petani dalam menjalankan usahanya. Sadjudi, (2009) menyatakan bahwa sifat kewirausahaan petani berpengaruh signifikan dengan kinerja usaha tani.

Kinerja adalah seperangkat hasil yang dicapai dan merujuk pada tindakan pencapaian serta pelaksanaan suatu pekerjaan yang diminta (Darmadji, 2011). Kinerja dapat dilihat dari keuntungan yang dihasilkan selama usaha. Dwi Larso, (2011) menyatakan bahwa kinerja petani sangat dipengaruhi oleh sifat kewirausahaan yang dimiliki, faktor sifat kewirausahaan ini mempengaruhi hingga 49\% terhadap kinerja usaha tani.Untuk itu, tidak dapat dipungkiri sifat kewirausahaan memang mempunyai fungsi penting sebagai motor penggerak kinerja petani dalam mengembangkan usaha taninya. Petani yang kurang dan belum mempunyai sifat kewirausahaan senantiasa kesulitan dalam kinerja usaha taninya, seperti mengelola dan mengembangkan diversifikasi usaha secara produktif ditengah potensi sumberdaya lokal yang melimpah. Untuk itu, tidak dapat dipungkiri sifat kewirausahaan memang mempunyai fungsi penting sebagai motor penggerak kinerja petani dalam mengembangkan usaha taninya.

Pertanian organik merupakan pertanian berwawasan lingkungan karena kegiatan pertanian yang dilakukan menggunakan bahan organik yang dapat menjaga kesuburan tanah dan memperbaiki kerusakan akibat pertanian anorganik (Syukur and Melati, 2012). Tujuan utama pertanian organik adalah menyediakan produk produk pertanian terutama bahan pangan yang aman bagi kesehatan produsen dan konsumennya serta tidak merusak lingkungan (Sutarni, Teguh.B.T. \& Bina, 2017).

Kelompok tani Tranggulasi berada di Dusun selongisor Desa Batur Kecamatan Getasan Kabupaten semarang, terletak pada ketinggian $\pm 1450 \mathrm{mdpl}$, dan mempunyai spesialisasi sayur organik. Kelompok tani ini mulai berpindah ke pertanian organik dimulai dari tahun 2000 dan dilakukan serentak pada tahun 2004 dengan jumlah anggota 32 orang. Awalnya didasari keterbatasan anggota kelompok dalam membeli pupuk dan pestisida kimia, namun sekarang menjadi pertanian yang banyak diminati dalam pertanian modern saat ini. Kelompok tani ini sudah memiliki sertifikat organik dari INOFICE dan menjalin kerjasama dengan Superindo di Kota Solo, Semarang, Yogyakarta dalam memasarkan produknya.

Berdasarkan masalah yang diuraikan diatas, penulis ingin mengetahui hubungan sifat kewirausahaan (percaya diri, berani mengambil risiko, kepemimpinan, keorisinilan) terhadap kinerja petani sayur organik di kelompok tani Tranggulasi, yang dijabarkan menjadi rumusan masalah bagaimana hubungan sifat kewirausahaan (percaya diri, berani mengambil risiko, kepemimpinan, keorisinilan) terhadap kinerja petani sayur organik di kelompok tani Tranggulasi.

\section{METODE PENELITIAN}

Jenis Penelitian. Jenis penelitian ini menggunakan jenis penelitian deskriptif kuantitatif dengan metode penelitian yang digunakan adalah metode survey. Penelitian dilaksanakan pada Maret 2019 s/d April 2019 di Dusun Selongisor Desa Batur Kecamatan Getasan Kabupaten Semarang. Pemilihan lokasi penelitian ini dilakukan secara sengaja (purposive).

Populasi. Populasi dalam penelitian ini adalah seluruh petani sayur organik anggota kelompok tani Tranggulasi sejumlah 32 orang. Teknik pengambilan sampel dengan pendekatan non probability sampling dengan menggunakan sampling jenuh (sensus), sehingga jumlah responden sebanyak 32 orang. Variabel bebas yang digunakan dan dianalisis dalam penelitian ini adalah sifat kewirausahaan terdiri dari empat indikator yaitu percaya diri (X1), berani mengambil risiko (X2), kepemimpinan (X3) keorisinilan (4) dan variabel terikat kinerja (Y). Pengukuran variabel penelitian menggunakan skala Likert 1-5 yang menunjukkan derajat kesetujuan mulai dari Sangat Tidak Setuju (STS = 1), Tidak Setuju (TS=2), Netral $(\mathrm{N}=3)$, Setuju ( $\mathrm{S}=4)$ dan Sangat Setuju ( $\mathrm{SS}=5)$. Pengumpulan data dilakukan dengan wawancara menggunakan instumen penelitian (kuisioner) yang sebelumnya telah diuji validitas dan reliabilitasnya. 
Prasetya \&Yuliawati : Hubungan Sifat Kewirausahaan dengan Kinerja Petani Sayur ....

Uji Validitas. Kuesioner yang dibuat tentunya harus dapat mengukur apa yang akan diukur dalam penelitian. Suatu kuesioner dikatakan valid jika pertanyaan pada kuesioner mampu mengungkapkan sesuatu yang akan diukur dalam penelitian tersebut. Uji Validitas dilakukan dengan membandingkan nilai $r$ hitung dengan $r$ tabel dengan nilai $\alpha=0,05$. Menurut Ghozali, (2012), kriteria pengukuran yang digunakan adalah :

a. Apabila $\mathrm{r}$ hitung $>\mathrm{r}$ tabel maka dapat disimpulkan bahwa kuesioner tersebut valid.

b. Apabila $r$ hitung < $r$ tabel maka dapat disimpulkan bahwa kuesioner tersebut tidakvalid.

Uji Reliabilitas. Kuesioner dikatakan reliable jika jawaban yang dipilih seseorang terhadap pertanyaan di kuesioner konsisten atau sama. Setiap alat ukur harus memiliki kemampuan untuk memberikan hasil yang konsisten, dimana reliabilitas dikatakan baik jika nilai Alpha Cronbach lebih dari 0,6 (Ghozali, 2012). Jika suatu variabel lebih dari 0,6 maka suatu variabel bisa dikatakan baik/reliable.

Teknik Analisis Data. Teknik analisis data yang digunakan adalah korelasi Rank Spearman $\left(\mathrm{r}_{\mathrm{s}}\right)$ dan uji t. Untuk menyimpulkan nilai korelasi $\left(\mathrm{r}_{\mathrm{s}}\right)$ yang diperoleh, digunakan interpretasi menurut Sugiyono (2014) yaitu jika nilai $r_{s}: 0,00-0,19$ hubungan sangat rendah, jika nilai $r_{s}: 0,20-0,39$ hubungan rendah, jika nilai $\mathrm{r}_{\mathrm{s}}$ : 0,40-0,59 hubungan sedang, jika nilai $\mathrm{r}_{\mathrm{s}}$ : 0,60-0,79 hubungan kuat dan jika nilai $\mathrm{r}_{\mathrm{s}}: 0,80-0,100$ hubungan sangat kuat.

\section{HASIL DAN PEMBAHASAN}

Karakteristik Responden. Petani sayur organik yang tergabung di kelompok tani Tranggulasi rata rata berumur 51 tahun atau berada pada interval 46-55 tahun yaitu berjumlah 14 orang atau $44 \%$, sedangkan yang berumur di bawah 46 tahun hanya 11 orang. Dari data tersebut dapat diketahui bahwa petani sayur organik di kelompok tani Tranggulasi anggotanya mayoritas sudah cukup tua atau hampir tidak produktif sehingga tingkat kinerjanya berkurang. Tingkat pendidikan rata - rata anggota kelompok tani Tranggulasi adalah SD yaitu $81 \%$ sedangkan yang berpendidikan S1 hanya satu orang yaitu ketua kelompok taninya saja. Luas lahan petani di kelompok tani Tranggulasi rata rata $1850 \mathrm{~m}^{2}$ yaitu di interval $500-1500 \mathrm{~m}^{2}$ sebanyak 46\%, $1600-2500 \mathrm{~m}^{2}$ sebanyak $37 \%$, dan yang memiliki lahan $>3500 \mathrm{~m}^{2}$ hanya 2 orang $(6 \%)$. Hal ini menunjukkan bahwa umumnya usahatani masih diusahakan pada skala usaha kecil.

Anggota kelompok tani Tranggulasi menanam beberapa jenis sayuran organik diantaranya brokoli, kol, selada, bit, daun bawang dan sawi dengan pola tanam tumpangsari. Rerata produksi brokoli per musim panen (80 hari) $457 \mathrm{~kg}$ dengan harga jual berkisar Rp 15.000,00/kg, produksi kol per musim panen (90 hari) $972 \mathrm{~kg}$ dengan kisaran harga jual Rp 4000,00/kg, produksi selada rata rata $167 \mathrm{~kg}$ per musim panen (60 hari) dengan kisaran harga jual Rp 6000,00/kg, produksi bit per musim panen (50 hari) hari $278 \mathrm{~kg}$ dengan kisaran harga jual Rp10.000,00/kg, produksi daun bawang per musim tanam (45 hari) $93 \mathrm{~kg}$ dengan harga jual $\mathrm{Rp}$ 13500,00/kg, produksi sawi per musim tanam (60 hari) $210 \mathrm{~kg}$ dengan harga jual Rp 4000,00/kg.Pendapatan rata rata petani per musim tanam sebesar $\mathrm{Rp} 39.066 .891$ per ha.

Uji Instrumen Penelitian. Uji Validitas. Hasil Uji validitas dalam penelitian ini sebanyak 32 responden, sehingga di dapatkan $r$ tabel 3,494. Dari hasil uji validitas semua skor dengan nilai signifikansi < 0,05 dan $r$ hitung > $r$ tabel $(0,3494)$ maka butir peryataan yang di buat di nyatakan valid.

Uji Reliabilitas. Hasil uji reliabilitas pada sifat Percaya Diri memiliki nilai Cronbach's Alpha sebesar 0,723, Keberanian Mengambil Risiko 0,712, Kepemimpinan 0,617, dan Keorisinilan 0,682. Dari empat variabel X yaitu Sifat Kewirausahaan dinyatakan reliabel.

Hubungan Sifat Kewirausahaan (Percaya diri, Keberanian mengambil risiko, Kepimimpinan, Keorisinilan) dengan Kinerja Petani. Hasil analisis korelasi rank Spearman terhadap variabel sifat kewirausahaan yang terdiri dari percaya diri $\left(\mathrm{X}_{1}\right)$, keberanian mengambil risiko $\left(\mathrm{X}_{2}\right)$, kepemimpinan $\left(\mathrm{X}_{3}\right)$, keorisinilan $\left(\mathrm{X}_{4}\right)$ dengan kinerja petani $(\mathrm{Y})$ disajikan pada Tabel 1. 
Tabel 1. Hubungan percaya diri $\left(\mathrm{X}_{1}\right)$, keberanian mengambil risiko $\left(\mathrm{X}_{2}\right)$, kepimimpinan $\left(\mathrm{X}_{3}\right)$, keorisinilan $\left(\mathrm{X}_{4}\right)$ dengan kinerja $(\mathrm{Y})$

\begin{tabular}{clccc}
\hline No & \multicolumn{1}{c}{ Variabel } & rs & $\begin{array}{c}\text { sig. } \\
(<0,05)\end{array}$ & Keterangan \\
\hline 1 & Percaya Diri $\left(\mathrm{X}_{1}\right)$ & $0,624^{* *}$ & 0,000 & Signifikan \\
2 & Keberanian mengambil Risiko $\left(\mathrm{X}_{2}\right)$ & $0,525^{* *}$ & 0,002 & Signifikan \\
3 & Kepemimpinan $\left(\mathrm{X}_{3}\right)$ & $0,501^{* *}$ & 0,004 & Signifikan \\
4 & Keorisinilan $\left(\mathrm{X}_{4}\right)$ & $0,575^{* *}$ & 0,001 & Signifikan \\
\hline
\end{tabular}

Sumber: Data Primer, 2019 (diolah)

Percaya diri merupakan sikap dan keyakinan petani untuk memulai, melakukan, dan menyelesaikan suatu tugas yang dihadapi oleh sebab itu kepercayaan diri menjadikan petani memiliki keyakinan sehingga memiliki kemampuan untuk kinerja yang baik. Nilai koefisien korelasi variabel percaya diri dengan kinerja sebesar 0,624 dengan tanda positif dan signifikan pada taraf kepercayaan 95\%. Hal tersebut menunjukkan bahwa percaya diri memiliki hubungan yang kuat dengan kinerja karena hasil korelasi pada interval 0,600 0,799 sesuai dengan interpretasi kuatnya hubungan korelasi menurut (Sugiyono, 2013). Percaya diri memiliki hubungan yang kuat karena kepercayaan diri seseorang yang berbaur dengan keterampilan, pengetahuan, dan kewaspadaan baik secara langsung maupun tidak langsung berpengaruh terhadap sikap mental petani, gagasan, karsa, inisiatif, kreatifitas, keberanian mengambil risiko, ketekunan, dan semangat kerja. Jadi semakin tinggi kepercayaan diri seseorang, semakin tinggi juga hasil yang didapatkan (Siswadi., 2013).

Keberanian mengambil risiko memiliki kaitan dengan kepercayaan diri sendiri, sehingga dapat diartikan semakin tinggi keyakinan petani akan kemampuan diri sendiri, maka semakin tinggi kesediaan petani untuk mengambil risiko yang memiliki potensi kegagalan untuk kinerja usaha taninya. Nilai koefisien korelasi variabel keberanian mengambil risiko dengan kinerja sebesar 0,525 dengan tanda positif dan signifikan pada taraf kepercayaan 95\%. Hal tersebut menunjukkan bahwa keberanian mengambil risiko memiliki hubungan sedang dengan kinerja karena hasil korelasi pada interval 0,400 - 0,599 sesuai dengan interpretasi kuatnya hubungan korelasi menurut (Sugiyono, 2013). Tanda positif menunjukkan bahwa hubungan antara keberanian mengambil risiko berbanding lurus dengan kinerja petani artinya semakin tinggi keberanian mengambil risiko, maka semakin tinggi kinerja petani sayur organik di kelompok tani Tranggulasi.

Nilai koefisien korelasi variabel kepemimpinan dengan kinerja sebesar 0,501 dengan tanda positif dan signifikan pada taraf kepercayaan 95\%. Hal tersebut menunjukkan bahwa kepemimpinan memiliki hubungan sedang dengan kinerja karena hasil korelasi pada interval 0,400 - 0,599 sesuai dengan interpretasi kuatnya hubungan korelasi menurut Sugiyono, (2013), tanda positif menunjukkan bahwa hubungan antara kepemimpinan berbanding lurus dengan kinerja petani, artinya semakin tinggi kepemimpinan maka semakin tinggi kinerja petani sayur organik di kelompok tani Tranggulasi. Seorang petani yang berhasil selalu memiliki sifat kepemimpinan, ia selalu ingin tampil beda, terlebih dulu, lebih menonjol dan dapat mempengaruhi orang lain. Hal ini dapat berhubungan dengan kinerja petani maupun dalam kelompok tani.

Keorisinilan memiliki hubungan terhadap kinerja petani seperti halnya petani yang memiliki sikap inovatif akan membuat pengusaha mampu menggunakan teknologi terbaru yang lebih efisien sehingga membuat kinerja usaha lebih baik. Penggunaan teknologi membuat proses produksi lebih cepat dan tidak membutuhkan banyak tenaga kerja, selain itu sifat kreatif dapa membuat petani mampu menghasilkan produk dengan kualitas yang lebih baik dengan biaya yang lebih murah. Nilai koefisien korelasi variabel kepemimpinan dengan kinerja sebesar 0,575 dengan tanda positif dan signifikan pada taraf kepercayaan 95\%. Hal tersebut menunjukkan bahwa keorisinilan memiliki hubungan sedang dengan kinerja karena hasil korelasi pada interval 0,400 - 0,599 sesuai dengan interpretasi kuatnya hubungan korelasi menurut 
Prasetya \&Yuliawati : Hubungan Sifat Kewirausahaan dengan Kinerja Petani Sayur ....

Sugiyono, (2013) Tanda positif menunjukkan bahwa hubungan antara keorisinilan berbanding lurus dengan kinerja petani, artinya semakin tinggi keorisinilan maka semakin tinggi kinerja petani sayur organik di kelompok tani Tranggulasi. Dalam kelompok tani Tranggulasi sifat keorisinilan ini berhubungan dengan usaha memajukan kelompok taninya seperti halnya pemasaran produk dari anggota kelompok, pengemasan dan pembuatan teknik baru dalam pertanian organik.

\section{KESIMPULAN DAN SARAN}

Sifat kewirausahaan berhubungan positif dan signifikan dengan kinerja petani sayur organik. Variabel sifat kewirausahaan percaya diri memiliki hubungan kuat dengan kinerja petani sayur organik, sedangkan keberanian mengambil risiko, kepemimpinan dan keorisinilan memiliki hubungan sedang dengan kinerja petani sayur organik. Pembinaan untuk meningkatkan sifat kewirausahaan perlu dilakukan di kelompok tani Tranggulasi yang masih dalam taraf kuat dan sedang karena dalam menghadapi pertanian berkelanjutan dan kemajuan jaman yang penuh persaingan, semakin menuntut pelaku sektor pertanian memiliki sifat wirausaha (enterpreneurship) agar dapat memperoleh hasil dan kinerja yang lebih besar dibandingkan usaha tani yang dilakukan sebelumnya.

\section{DAFTAR PUSTAKA}

Darmadji (2011) 'Analisis Kewiausahaan Sebagai Variabel Baru Penentu Kinerja Usaha Tani. Malang', Universitas Widyagama Malang.

Dirlanudin (2010) 'Perilaku Wirausaha dan Keberdayaan Pengusaha Kecil Industri Agro', Institut Pertanian Bogor.

Dwi Larso (2011) 'Identifikasi Faktor-Faktor yang Mempengaruhi Kinerja UKM Catering di Kota Bandung', Jurnal Manajemen Teknologi,10.2.

Ghozali, I. (2012) 'Aplikasi Analisis Multivariat dengan Program IBM SPSS 20 (Edisi keenam). Semarang: Universitas Diponegoro. Sugiyono.(2008)’, Metode Penelitian Bisnis.

Puspitasari, Rina (2013) 'Strategi Komunikasi Kader Pendamping Produktivitas dan Kewirausahaan (KP2KW) dalam Memotivasi Industri Kecil Menengah (IKM) di Kota Bontang', eJournal Ilmu Komunikasi., 1 No. 2.

Sadjudi (2009) 'Pengaruh Kewirausahaan Terhadap Kinerja Usaha Tani Tembakau di Kecamatan Ganti Warno Kabupaten Klaten’, Aplikasi Manajemen, 7(2):401

Siswadi. (2013) ‘Analisi Faktor Internal, Eksternal dan Pembelajaran', Manajemen Bisnis , (13)1.

Sugiyono (2013) 'metodologi penelitian kuantitatif kualitatif dan R \& D', in Bandung: Alfabeta. doi: 10.1164/rccm.200409-1267OC.

Sutarni, Teguh.B.T. \& Bina, U. (2017) 'Preferensi Konsumen Terhadap Atribut Produk Sayuran Organik Di Kota Bandar Lampung.', Jurnal Penelitian Pertanian Terapan, 17(3):, pp. 203-211.

Syukur, M. and Melati, D. M. (2012) 'Pengembangan Sayuran Organik', Pengembangan Pertanian Organik di Indonesia, (Mayrowani 2012), pp. 175-191. 